\title{
Zusatz-Reißverschluss für die rasche Beinbeutelentleerung
}

\author{
Für Patienten mit einer Harnblasenlangzeitdrainage ist eine diskrete und rasche Entleerung
} des Beinbeutels oft schwierig. Was hier helfen kann, lesen Sie in folgendem Tipp.

Viele Patienten klagen bei einer Harnblasenlangzeitdrainage etwa durch einen suprapubischen Blasenfistelkatheter über die geringe Kapazität des häufig tagsüber verwendeten Beinbeutels. Diese macht die hochfrequente Entleerung und das jeweilige Entkleiden notwendig, was sich bei mobilen Patienten manchmal nicht diskret anstellen lässt.

Einer unserer Patienten hatte hier durch einen Trick Abhilfe entwickelt: Er ließ in alle seine Hosen seitlich in Höhe des Beinbeutels einen zusätzlichen Reißverschluss durch eine Änderungsschneiderin einbringen (Lohn und Materialkosten: 10 Euro) ( Abb.1, ○ Abb. 2). Dies ermöglicht ihm die rasche und diskrete Beinbeutelentleerung ohne komplettes Entkleiden etwa vor dem Urinal einer öffentlichen Toilette oder in der Natur und gab ihm damit nach eigenem Bekunden ein kleines Stück Lebensqualität zurück.

\section{PD Dr. Andreas Wiedemann, Witten}

Korrespondenz:

PD Dr. Andreas Wiedemann

Urologische Klinik

Evangelisches Krankenhaus

im Diakoniewerk Ruhr gGmbH

Lehrstuhl für Geriatrie

der Universität Witten/Herdecke

Pferdebachstr. 27

58455 Witten

Tel.: +49/2302/175-2521

awiedemann@diakonie-ruhr.de

Interessenkonflikte: PD Dr. Wiedemann: Beratungstätigkeit: Dr. Pfleger, Pfizer; Vortragstätigkeit: Allergan, AMS Deutschland, Astellas, Berlin-Chemie, Jansen, Lilly Deutschland, Dr. Pfleger, Pfizer, PohlBoskamp; Studienfinanzierung: AMS Deutschland

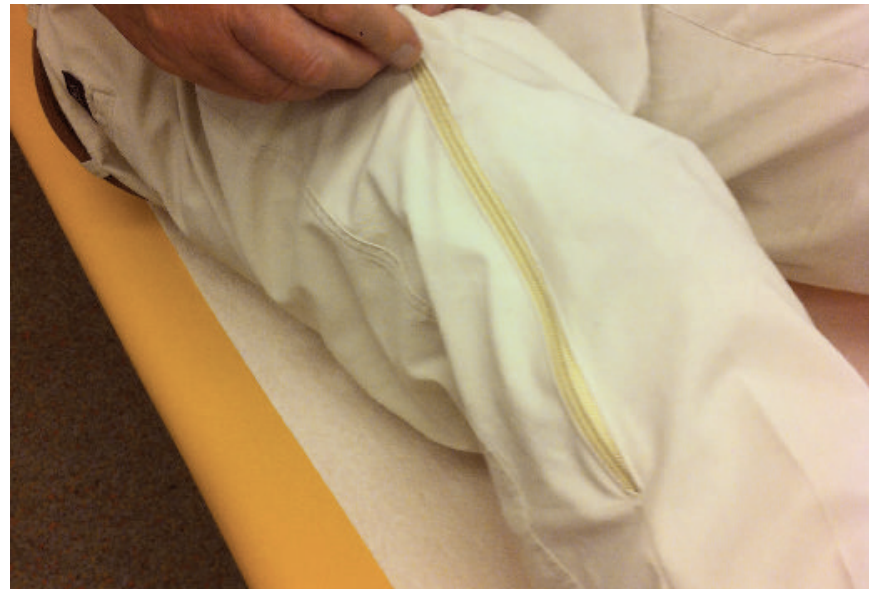

Abb. 1 Ein in die Hose über dem Beinbeutel eingearbeiteter Reißverschluss erlaubt diskreten Zugriff auf das Ablassventil.

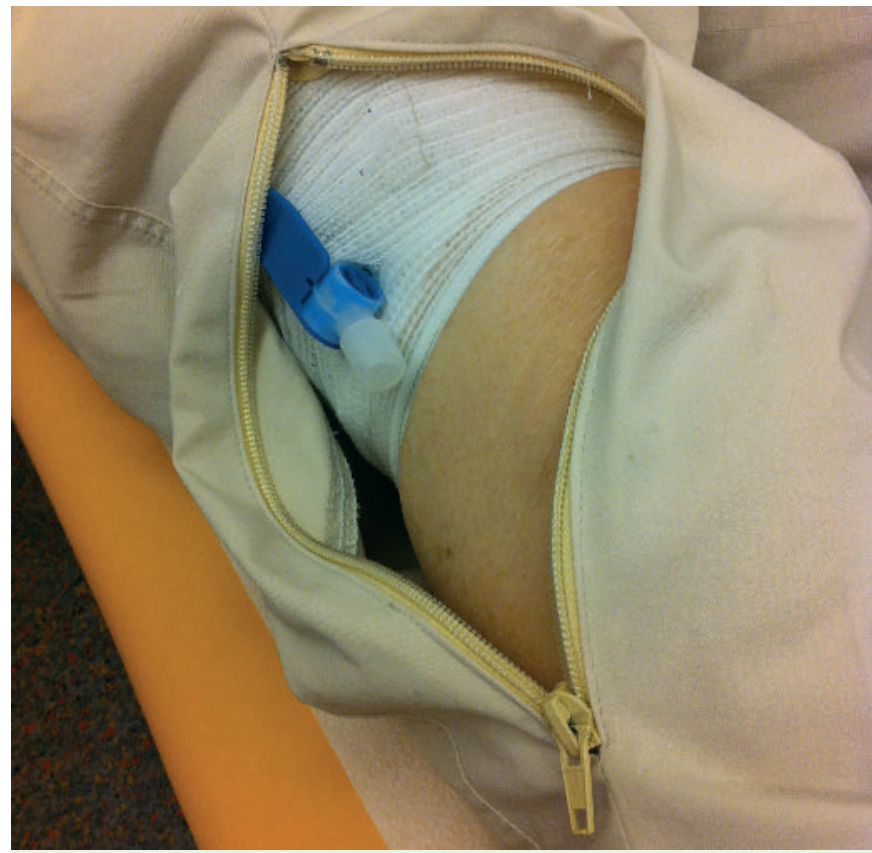

Abb. 2 Der Beinbeutel kann durch den Reißverschluss hindurch ohne gänzliches Entkleiden entleert werden. 